\title{
Analysis on the Development Path of Music Education in Rural Areas under the Influence of COVID-19 Outbreak
}

\author{
Taozi Guo \\ Sichuan University Jinjiang College
}

\begin{abstract}
In 2020, the sudden COVID-19 outbreak brought huge economic and life losses to the whole world, affecting all walks of life in China, including the education industry which suffered from many problems, such as students' learning needs for medical health knowledge, publicity needs for public health safety, psychological and mental health protection needs, and online learning needs based on internet accelerated speed .In rural China, some rural students have physical and mental health problems due to the problems of rural population structure, infrastructure construction, talent mobility, etc. In this period, schools should pay more attention to the psychological counseling and education of rural students, on which music education has a positive impact. During the epidemic period, rural education construction around cultural revitalization was gradually implemented under the background of China's full implementation of rural revitalization strategy. In the construction of rural education, music education is an important cornerstone to promote the all-round development of students, build a rural cultural atmosphere and inherit the excellent national culture. With the change of social environment, the country music education welcomes new opportunities, but also faces some practical problems to be solved.First of all, the literature on the COVID-19 outbreak and rural music education is studied and analyzed through on-the-spot visits and investigation on the current situation of music education in rural schools. Then, interviews and records are made with rural music teachers and students. Next, discussions are made on the construction of rural music teachers, information technology of music education, cultural life of the rural masses and other aspects. Finally, relevant strategies for the development of rural music education are put forward.The COVID-19 outbreak has narrowed the channels for rural music teachers' professional promotion, and caused some problems in rural students' mental health. In addition, rural schools have some shortcomings in online learning and information education based on internet plus, and the number of rural cultural performances and activities has decreased.Education managers should take corresponding management measures to innovate the music education model with the aid of modern teaching technology. At the same time, rural schools need to maintain long-term cooperation with all sectors of society and cooperate in public health, medical resources, education resources, curriculum innovation, rural cultural activities and other aspects to ensure the real implementation, promotion and development of music education, aesthetic education and art education in the countryside during the COVID-19 epidemic.
\end{abstract}

Keywords:COVID-19 outbreak, country music education, country music teacher, educational informationization, mass culture

In the report of the 19th National Congress of the Communist Party of China, it is pointed out that "rural revitalization" is a national strategic measure. With the revitalization of culture, rural music education has also ushered in new opportunities and faced new challenges. At present, country music education remains a weak point in the basic education in China under the impact of COVID-19 outbreak, which can be improved by applying good quality educational resources, methods, and technologies to rural music education and the life of rural culture, so as to close the urban-rural gap and promote the benign development of country music education. As music education has a positive impact on students' character, aesthetic taste and life attitude in the stage of compulsory education, the good development of rural music education is of great significance in improving the quality of rural aesthetic education and personality education[1,2].

\section{Building a Team of Country Music Teachers}

1.1 The practical problems in the building of rural teachers' team

Since the 18th National Congress of the Communist Party of China, the Party and the state have attached great

ISSN: 0010-8189

(C) CONVERTER 2021

www.converter-magazine.info 
importance to the construction of rural teachers' team, and have promoted a series of policies from the aspects of treatment, system, management and professional development based on the problems existing in teachers' practical work. However, the gradual improvement of rural infrastructure, ecological environment and living standards has also brought new changes and problems to rural education and rural music education [3].

The music course in the compulsory education stage has its main function in fostering students' interest in music, perception of beauty, pottery emotional manipulation, etc., while the music education content and tasks in this stage are mainly performed by school music teachers. Country music teachers have more important responsibilities because students have fewer opportunities to access music education than urban students due to the gap between urban and rural development. The increasing per capita income promotes the improvement of living standards and per capita consumption in rural areas, and people's demand for education, culture and entertainment consumption is also increasing (Fig. 1), which is a new opportunity for the development of rural music education. However, there are still some practical problems to be solved in the structure, work tasks and professionalism of rural teachers [4].

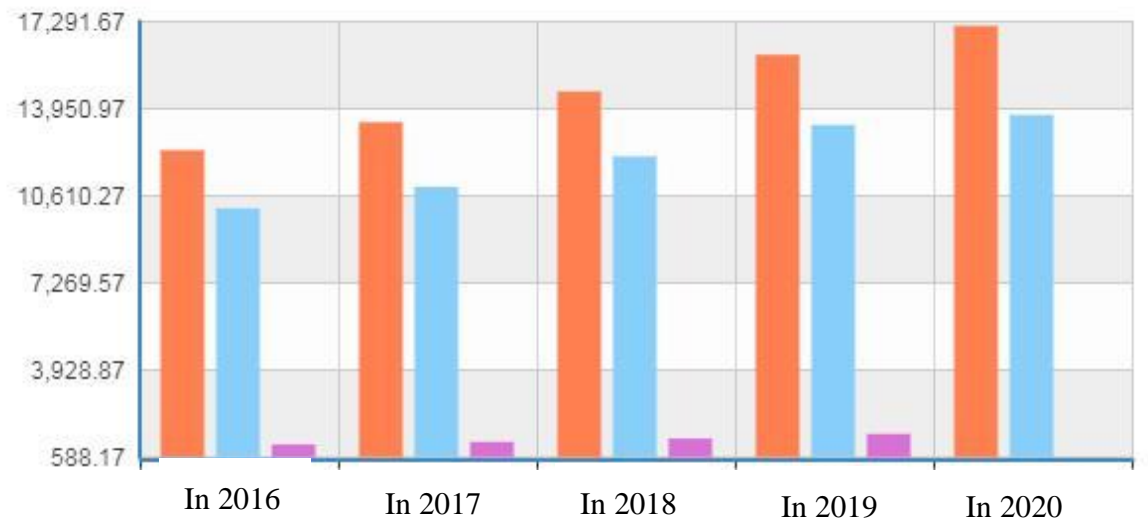

Per capita disposable income of rural residents (yuan)

Per capita consumption expenditure of rural residents (yuan)

Per capita expenditure on education, culture and entertainment of rural residents (yuan)

Fig. 1 The per capita disposable income, the per capita consumption expenditure and the per capita expenditure on education, culture and entertainment of rural residents in the past five years (data from the National Bureau of Statistics)

\subsubsection{Unstable rural music teachers}

The composition of rural music teachers is relatively complex. The school has both full-time teachers and substitute teachers, among which the substitute teachers also include those not majored in music.As substitute teachers have no background of professional music education, it is difficult to guarantee professionalism in their teaching. Meanwhile, other part-time teachers employed by the school are difficult to be recorded in the statistical analysis of the teaching staff due to their changeability and mobility, which hinders understanding the current situation of the teaching staff and optimizing the structure of the teachers. Full-time music teachers in rural schools also have differences in learning experience, professional level and comprehensive accomplishment.

\subsubsection{Complex tasks of rural music teachers}

The workload of teachers in rural schools is generally large because firstly there are fewer teachers. Compared with urban schools where music teachers are usually subdivided into various specialties, such as instrumental, dance, vocal, etc., rural schools often have one teacher assuming all the positions, with more class hours per week. Secondly, the teachers should undertake other tasks besides their own teaching work, such as various evaluation, inspection, performance and publicity tasks of the school. Music teachers usually play main roles in such activities

ISSN: 0010-8189

(C) CONVERTER 2021 
due to their professional expertise and other reasons, resulting in complicated work content, impacted work efficiency, and poor work experience.

\subsubsection{To-be-strengthened professionalism of rural music teachers}

Rural music teachers have great differences in professional level, scientific research and teaching ability, professional quality and so on because of their different backgrounds. Due to the shortage of teachers in schools, the relatively closed environment, and the inability to communicate with peers conveniently, the COVID-19 epidemic has also reduced the opportunities for rural school music teachers to communicate and learn with others, they are unable to summarize and reflect on their own music teaching work in a timely manner. In addition, in the past, music courses in rural schools are generally ignored, so some music teachers are temporarily unable to change their thinking and take the initiative to improve their own quality. However, music education requires teachers to have a high level of professional ability, moral sentiment and comprehensive quality. If they do not have a good level, it is difficult to express the aesthetic feeling of music in teaching, let alone using music to educate students.

\subsection{Guarantee for the professional development of rural musicteachers}

According to the data published by CNKI (Fig. 2), the research on the key word of "country music education" has been increasing year by year, with the fastest growth in 2019, reaching the peak, indicating that the attention paid to country music education is getting closer and closer under the guidance of national policies. Teachers' professional development is mainly reflected in the cultivation and promotion of professional ethics, professional knowledge, professional ability, etc. Therefore, it is the key to solve the problem of improving the quality of rural music education to provide professional guidance and resource guarantee for rural music teachers by the state and all sectors of society.

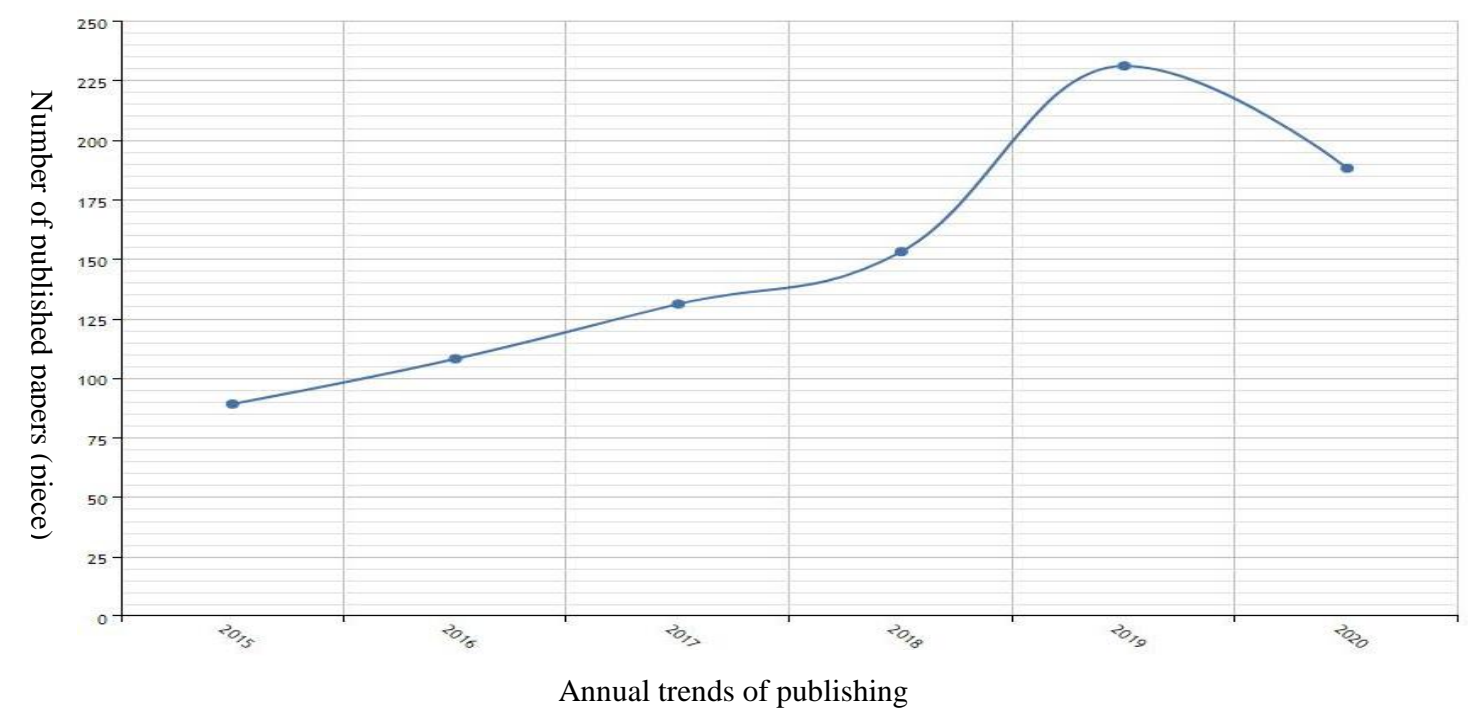

Fig. 2CNKI annual publication data with the key word "country music education"

1.2.1 Paying attention to the treatment of teachers and guaranteeing their welfare

As the living conditions in the villages are poorer than those in the cities, and the infrastructure in all aspects needs to be improved, it is very difficult for the frontline teachers to insist on the position of education in the villages, which requires courage and dedication. However, from the perspective of sustainable development of talents, it is necessary to focus on the improvement of rural education by retaining talents. Therefore, the national and local governments have successively issued various policies and made a series of improvements around the "Rural Teacher Development Plan", but there is still a large gap compared with urban areas. The education management department may establish some safeguard mechanisms and systems, carry out regular assessment or quantitative 
assessment on the professional teaching process of the country music teachers, implement measures such as rewards or personnel allowances and subsidies, and reform of professional title assessment, etc., so as to increase the motivation of the country music teachers to improve their own level.

1.2.2 Providing space for career development and promoting teachers' communication and learning

In rural schools, there are many familieswith financial difficulties and left-behind children. The students from those families have different degrees of anxiety, loneliness and depression due to the influence of COVID-19 outbreak. Therefore, teachers also need to pay more attention to thm, because they are usually more sensitive, have more emotional needs, and have a certain psychological basis in the perception of music. Rural schools can, as far as possible, involve music teachers and students together in transmitting excellent cultural thoughts, relieving students' emotions, comforting their souls, participating in cooperation and displaying achievements, so as to enhance the confidence and achievement of teachers and students.

Rural schools should fully recognize the important position of music education in basic education and fully affirm the value and role of country music teachers in education so that they can get out of the multifarious extracurricular work and devote themselves to teaching research just like teachers in other disciplines. Only in this way can they play a role of educating people. At the same time, they should formulate training plans for country music teachers, complete school-based teaching and research, allow outside experts and famous teachers to guide them, accept advanced teaching methods and concepts, and communicate and collaborate with local education departments and universities. Local schools can also increase the intensity of running schools by means of collectivization, and adopt one-to-one assistance mechanism for local high-quality schools to rural schools, so that talents can flow with each other, and problems such as shortage of teachers and brain drain can also be solved.[1]

\section{Application of Informatization in Country Music Education}

According to the requirements of Ten-year Development Plan of Educational Informatization (2011-2020), it is necessary to make full use of the power of information technology in modern education, and attach great importance to informatization teaching in teaching process and form. Looking back on the development of educational informatization in recent ten years, the integration of information technology and education and teaching is in a period of change, which requires a deep breakthrough in details. The outbreak of the COVID-19 epidemic in 2020 has promoted the positive development of online education in China. The use of information in music education can enrich the reserve of teaching resources, expand teachers' professional vision, enhance the innovation of teaching process, and improve students' participation.

\subsection{Informatization of music education can improve curriculum system}

The informationization of music education can enable schools to carry out more abundant music appreciation courses and music creation courses. In music appreciation class, teachers can use information technology to select the most suitable teaching resources, supplement the traditional classroom playing and listening modes, and practice targeted audio-visual singing for rural students. In addition, rich network audio-visual resources and massive open online course resources can improve students' appreciation ability and aesthetic level. At the same time, information technology can also improve the interaction between teachers and students and the communication between students, so that teachers can bring their creativity into play and develop new teaching methods. With the help of information technology, simple music creation courses can be carried out. For example, students can try some simple and easy-to-use music creation software, such as portable bands and Garage band bands that can be operated directly on a tablet computer. Teachers can guide the students in the process of composing music, comment on and display the achievements of students' works, etc. They can also use professional music editing software such as SONAR and CUBASE to input melodies, rhythms, beats, harmony and timbre in music elements for students to display. Music appreciation and creating courses can diversify music courses, make up for the lack of professionalism in music teaching in the past, and bring valuable music

ISSN: 0010-8189

(C) CONVERTER 2021

www.converter-magazine.info 
participation experience to students, so that they can master the theoretical knowledge and skills of music quickly.

\subsection{Informationization of music education can improve students' learning mode}

With the continuous investment in education funds, some rural schools should complement their classrooms and teaching equipment in the field of art education, such as intelligent piano classrooms, multimedia electronic classrooms, small musical instruments, etc., which, in combination with information technology, can enable students to actively use and think with the aid of platforms, and at the same time release teachers' teaching pressure in traditional class rooms. Teachers can popularize the use of some notation software for students, so that teachers and students can follow the platform to read, sing, play, arrange and so on. For rural students, they can participate in music activities in person, and can intuitively feel their own works and sound effects, which is a very good learning experience and can greatly improve their interest. Teachers or schools can also use network media, self-media, QQ group, WeChat group and other means to regularly display students' music works and learning achievements and send them to parents and society to arouse social attention. In this way, positive support from all walks of life can be gained.

\subsection{Rural music teachers' education information learning needs to be strengthened}

Compared with cities, the degree of informatization in rural schools is relatively low, and some rural teachers and substitute teachers are still unable to adapt to the mode of informatization teaching. Although information-based teaching equipment has been built in some rural schools, they perform practically no function due to low frequency of use. During the visit and communication with music teachers in rural schools, it is found that most young teachers have a high degree of acceptance, but they occasionally adopt information-based teaching because they do not have relevant professional training in teaching methods. However, older teachers refuse information-based teaching because they can't use it. Therefore, it seems that in order to popularize information education in rural schools in an all-round way, besides building hardware conditions, experts and professionals should be invited to provide professional training and guidance to teachers. Schools and teachers should, through the investigation of rural education, identify targeted courses that meet the basic situation of local students and students' learning ability, and provide students with appropriate teaching contents from the perspective of disciplines and social real life.[2]

\section{Enriching Rural Cultural Life}

Under the background of rural revitalization strategy, the route of artistic revitalization of rural can shape rural social environment and spread rural culture. With the country's emphasis on cultural undertakings, the quality of life of the people in rural areas has improved, and more and more public cultural infrastructure has been built (Fig. 3), especially the performance venues at and below the county level, which have the fastest growth and are the main growth points of all art performance venues. In this way, the rural masses can also have the opportunity to participate in cultural activities. Therefore, on the basis of building a public cultural platform, new public cultural activities and services can be added to rural life, which can not only meet the spiritual and cultural needs of rural residents, but also provide a solid foundation and cultural soil for rural music education.

ISSN: 0010-8189

C CONVERTER 2021

www.converter-magazine.info 


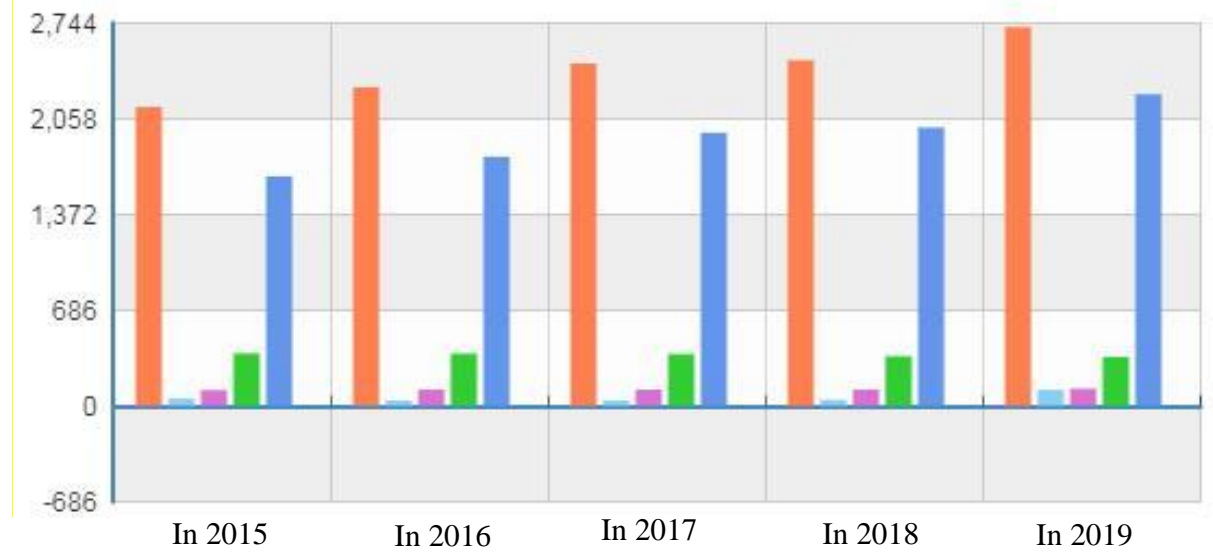

Fig. 3 Number of artistic performance venues at all levels

Number of art performance venues

Number of concert halls

Number of provincial, district and municipal art performance venues

Number of local and municipal art performance venues

Number of artistic performance venues in counties, cities and below

According to the Opinions on Promoting the High-quality Development of Public Cultural Services jointly issued by the Ministry of Culture and Tourism, the National Development and Reform Commission and the Ministry of Finance a few days ago, it is proposed to strengthen rural cultural governance, appropriately expand comprehensive rural cultural services, strengthen the protection and utilization of rural intangible cultural heritage, and carry out rural art popularization activities to improve the quality of rural cultural construction.

\subsection{Rural culture and art festival}

In recent years, local governments have attached great importance to rural publicity and development, among which holding rural culture and art festivals is an important means to develop tourism resources, attract social attention, increase external investment opportunities, and also a good way to enrich the cultural life of rural residents. With the support of local traditional folk culture and art, they can create a distinctive rural culture and tourist brand. When cultural and artistic activities have made significant gains and the quality of life of the residents has been improved, more and more people will become aware of the power and value of culture. In the long run, residents in the villages will become increasingly enthusiastic about cultural and artistic learning, which will also provide a basis for promoting the development of rural music education.

\subsection{Actively participation in construction of rural culture by local colleges and universities}

Colleges and universities can, relying on scientific research projects, use their professional advantages, research level, teaching quality and teaching staff to provide services for the benefit of the people, and use high-quality cultural influence to serve the construction of rural culture. Local colleges and universities, with focus on training applied talents, should give full play to their academic advantages in art and education, inject fresh blood into rural culture with scientific research projects and students' voluntary service model, increase students' social practice opportunities, and spread social influence, such as participating in rural community cultural services, public welfare classes, cultural performances, etc., bringing high-level cultural and artistic activities into the countryside and expanding rural students' horizons.[3]

ISSN: 0010-8189

(c) CONVERTER 2021 


\section{Conclusions}

In summary, under the background of the country's increasing emphasis on rural education, while doing a good job in the prevention and control of COVID-19 epidemic, aiming at the problems existing in China's rural music education, it is necessary not only for education managers to take corresponding management measures, but also for modern teaching techniques to innovate music education models. At the same time, rural schools need to maintain long-term cooperation with all sectors of society, and cooperate in public health, medical resources, educational resources, curriculum innovation, rural cultural activities and other aspects to ensure that music education, aesthetic education and art education are truly implemented, promoted and developed in rural areas during the COVID-19 epidemic.

\section{References}

[1] H. Xiao, Practical Strategies for Teacher Team Construction of Country Music. Journal of Hunan First Normal University, 2020.

[2] Y. Z. Yin, Realistic Bottlenecks and Solution Paths for Informatization of Country Music Education. Social Scientist, 2021.

[3] X. M. Ma, Strategies of Poverty Alleviation by Music Culture to Promote Aesthetic Education in Rural Areas. The World of Music, 2020.H. H. Lei, Thoughts on Rural Prevention and Control of New Crown Pneumonia. Chinese Journal of Social Medicine, 2021.

[4] X. M. Ma, Strategies of Poverty Alleviation by Music Culture to Promote Aesthetic Education in Rural Areas. The World of Music, 2020. 